\title{
Association of Ki-67 Proliferative Index with Clinico-Pathological Features of Non-Hodgkin's Lymphoma Classified According to WHO (2008)
}

\author{
Matadeen Meena ${ }^{1 *}$, Jayanti Mehta ${ }^{2}$ \\ ${ }^{1 *}$ Resident, 2 Professor, \\ Department of Pathology, SMS Medical College, Jaipur, Rajasthan, India.
}

\begin{abstract}
Objective: To assess the value of Ki-67 proliferative index (PI) in non-hodgkin's lymphoma (NHL) in relation to clinicopathological features.

Materials and Methods: Immunohistochemical (IHC) method was used to detect the expression of Ki-67 in 103 formalinfixed, paraffin-embedded tissue sample of $\mathrm{NHL}$ according to WHO classification (2008). Ki-67 PI with cutoff $45 \%$ assessed in relation to age, gender, site of involvement, B symptoms, Ann Arbor stage, lactate dehydrogenase (LDH) level, performance status (PS) and international prognostic index (IPI).

Results: Significant correlation was present between high Ki67 index and B symptoms, increase LDH level and IPI. Mean Ki-67 index included 26 for CLL/SLL, 30.6 for plasma cell neoplasm, 45 for follicular lymphoma, 28.75 for mantle cell lymphoma, 25 for MALT Iymphoma. The mean Ki-67 index was highest in burkitt's lymphoma (94.3). Mean Ki-67 index were 58.02 for diffuse large B cell lymphoma, 74.2 for lymphoblastic lymphoma, 46.9 for T cell lymphoma (NOS) and 51.6 for anaplastic large cell lymphoma.
\end{abstract}

Conclusions: Ki- 67 index is a valuable IHC marker to

\section{INTRODUCTION}

Lymphomas are divided into two categories, Hodgkin's lymphoma and Non-Hodgkin's Lymphoma (NHL). ${ }^{1} \mathrm{NHL}$ is a broad category consisting of B-cell and T-cell type, comprises $85 \%$ and $15 \%$ respectively. Clinically $\mathrm{NHL}$ is categorized into indolent group \& aggressive group. Indolent group are slow growing tumours with relative resistance to chemotherapy. It includes the small lymphocytic lymphoma, low grade follicular lymphoma and mantle cell lymphoma. Aggressive group comprises Burkitt's lymphoma, lymphoblastic lymphoma and diffuse large B cell lymphoma. ${ }^{1}$ Clinical variables like age, sex, Ann Arbor stage, B symptoms, site of involvement and lactate dehydrogenase together with proliferative index are important in diagnosis, grading and determination of prognosis of patient's outcome in $\mathrm{NHL}$. Proliferation is a key feature of the progression of Tumours. Proliferation is estimated by the Immunohistochemical assessment of the nuclear antigen $\mathrm{Ki}-67 .^{2} \mathrm{Ki}-67$ is expressed during the active phases of cell cycle in $\mathrm{G} 1, \mathrm{~S}, \mathrm{G} 2$, and mitosis. During interphase it can be detected within the nucleus while in mitosis it is detected on the chromosomal surface. Therefore Ki-67 is an excellent marker for determining the growth fraction of a given cell population. ${ }^{3}$ Tumour progression and malignancy are associated with increased angiogenesis and higher Ki-67 PI is associated with poor prognosis in solid and haematological malignancies. ${ }^{4} \mathrm{Ki}-67 \mathrm{PI}$ is helpful in the prediction of disease stage distinguish indolent from aggressive lymphomas. High Ki-67 PI has a significant role to establish the proliferative activity of tumor as prognostic index marker along-with clinical parameters.

Keywords: Ki-67 proliferative index, Non-hodgkin's lymphoma.

\section{${ }^{*}$ Correspondence to:}

Dr. Matadeen Meena

Resident, Department of Pathology, SMS Medical College, Jaipur, Rajasthan, India.

\section{Article History:}

Received: 02-06-2016, Revised: 12-06-2016, Accepted: 17-06-2016

\begin{tabular}{|l|c|}
\hline \multicolumn{2}{|c|}{ Access this article online } \\
\hline $\begin{array}{l}\text { Website: } \\
\text { www.ijmrp.com }\end{array}$ & \\
\hline DOI: & \\
10.21276/ijmrp.2016.2.4.024 & \\
\hline
\end{tabular}

and progression. Todays the Ki-67 positivity by $\mathrm{IHC}$ is the most popular method to determining the growth fraction of benign \& malignant cell population. ${ }^{4}$ Moreover, a positive correlation exist between prognosis and proliferation rates in chronic $B$ cell and $T$ cell lympho-proliferative disorders. ${ }^{5}$ The diagnostic criteria of Ki-67 PI approaches $100 \%$ in Burkitt's and atypical Burkitt's lymphoma. ${ }^{6}$ Aggressive lymphoma are associated with higher expression of $\mathrm{Ki}-67$ proliferation index in comparison to indolent lymphoma. Hence Ki-67 PI has clinical significance in diagnosis and determination of prognosis of NHL. This study was conducted to assess $\mathrm{Ki}-67 \mathrm{PI}$ in tissue sections for $\mathrm{NHL}$ with correlation to clinical and pathological parameters in NHL patients, to predict the behavior of disease at the time of presentation.

\section{MATERIAL \& METHODS}

The present study was carried-out in 103 patients with $\mathrm{NHL}$, which were categorized according to WHO classification (2008) of lymphoid neoplasms by immunohistochemistry from the period of January 2014 to December 2015 at department of pathology, SMS Medical College Jaipur. Patients with available records are included in our study. Previous diagnosed cases of NHL, HIV positive patients \& patients with previous history of low grade lymphoma are excluded. Routinely stained hematoxylin and eosin (H\&E) slides were reviewed. Histopathological sub-typing \& 
grading was performed based on the criteria described in the WHO (2008) working formulation. Immunohistochemical (IHC) stains using antibodies against CD 20, CD 3, CD 10, CD 5, CD 23, CD 21, BCL2, Ki-67 were done. Other markers including $C D$ 79a, ALK, CD 43, CD 30 and CD 15, PAX 5, MUM1, CD38, Kappa and Lamda were done in selected cases.

\section{Immunohistochemistry ${ }^{7}$}

Serial 3 to $4 \mu \mathrm{m}$ sections were cut from the paraffin block, mounted on positively charged slides. Keep the slides at $60^{\circ}-70^{\circ} \mathrm{C}$ temperature in oven for 30-40 min. Put the slides in xylene for 2 changes, each change for $10 \mathrm{~min}$. Then put the slides in alcohol for 2 changes, each change for $10 \mathrm{~min}$. Keep the slides in distilled water for $5 \mathrm{~min}$. Then put the slides in peroxidase solution for 10 $15 \mathrm{~min}$. (methanol $97 \mathrm{ml} \& \mathrm{H}_{2} \mathrm{O}_{2} 3 \mathrm{ml}$ ). Keep slides in tris buffer solution for 2 changes; each change for $5 \mathrm{~min}$. Antigen retrieval is done in following steps.

- Take $600 \mathrm{ml}$ distilled water in declocking chamber

- The slides are arranged in slide holder and put in (retrieval box) citrate buffer

- Slides are kept in a de-clock chamber and the chamber is closed.

- The temperature of the chamber is set at $125^{\circ} \mathrm{C}$.

- First beep comes after 15-20 minutes when temperature reaches $125^{\circ} \mathrm{C}$.

- Then, after first beep, push start/off button.

- After second beep, de-clocking chamber is opened, at that time temperature is near $89^{\circ}-90^{\circ} \mathrm{C}$.

Slides are kept at room temperature (20 minute) for cooling. Wash the slides with tris buffer. Mark the sections by PEP pen. Apply background snipper 3-4 drops for 15 minutes. Wash slides with tris buffer 2 times with the help of wash bottle. Apply primary antibody for 1 hour. Wash slides with tris buffer. Apply probe for 15 minutes. Wash with tris buffer. Apply polymer for half an hour. Wash with tris buffer. Apply $D A B$ for 5 minutes (1drop DAB chromogen along with $1 \mathrm{ml}$ of $D A B$ chromogen solution). Wash with de-ionised water. Slides kept in haematoxylin for 2 minutes. Slides kept in running tap water for 5 minutes. Alcohol -2 changes - each change for 5 minutes. Xylene -2 changes - each change for 10 minutes. The slides are mounted with DPX.

\section{Quality control of $\mathrm{IHC}^{8}$}

Negative control for immunostaining consisting of histological section of each case processed without the addition of primary antibody were prepared for each antigen, along with a positive control section prepared with each $\mathrm{IHC}$ run than staining result were evaluated.

\section{Assessment of Ki-67 indices ${ }^{9}$}

Immunohistochemical results were scored semi-quantitatively. For Ki-67, nuclear pattern were considered positive. Hot spots of neoplastic cells are observed and Proportion of Ki-67 positive cells were counted in 1000 cells \& percentage is taken out. A cut-off value of $45 \%$ was used to differentiate high versus low proliferative activity.

\section{Statistical analysis}

The data was analyzed using SPSS version 20 for windows software program. Chi-square test used for statistical analysis to assess the relationship of clinical parameters. Ki-67 PI using cutoff value of $45 \%$ and the mean Ki-67 PI within the NHL groups was tested by one way analysis of variances (ANOVA). $P$ value $<0.05$ was considered significant.

Table 1: Ki-67 PI in relation to clinical parameters

\begin{tabular}{|c|c|c|c|c|c|}
\hline & & $\begin{array}{c}\mathrm{Ki}-67 \\
\mathrm{Pl}<45 \%(\mathrm{~N})\end{array}$ & $\begin{array}{c}\mathrm{Ki}-67 \\
\mathrm{P} \mid>45 \%(\mathrm{~N})\end{array}$ & Total & $P$ value \\
\hline \multirow[t]{2}{*}{ Age } & $<60$ years & 36 & 42 & 78 & 0.22 \\
\hline & $>60$ years & 15 & 10 & 25 & \\
\hline \multirow[t]{2}{*}{ Gender } & Male & 39 & 38 & 77 & 0.69 \\
\hline & Female & 12 & 14 & 26 & \\
\hline \multirow[t]{2}{*}{ Anatomical site } & Nodal & 29 & 21 & 50 & 0.09 \\
\hline & Extra-nodal & 22 & 31 & 53 & \\
\hline LDH & Normal & 34 & 3 & 37 & 0.001 \\
\hline Level & High & 17 & 49 & 66 & \\
\hline \multirow[t]{2}{*}{ Ann Arbor stage } & $|\&| \mid$ & 33 & 28 & 61 & 0.25 \\
\hline & III \& IV & 18 & 24 & 42 & \\
\hline \multirow[t]{2}{*}{ B symptoms } & Present & 12 & 36 & 48 & 0.001 \\
\hline & Absent & 39 & 16 & 55 & \\
\hline Performance & 0,1 & 38 & 40 & 78 & 0.77 \\
\hline Status & $2,3,4,5$ & 13 & 12 & 25 & \\
\hline International & Low risk & 27 & 12 & 39 & 0.001 \\
\hline \multirow[t]{3}{*}{ prognostic index (IPI) } & Low intermediate risk & 12 & 23 & 35 & \\
\hline & High intermediate risk & 11 & 9 & 20 & \\
\hline & High risk & 1 & 8 & 9 & \\
\hline
\end{tabular}


Table 2: Ki 67 proliferative index (PI) in relation to subtypes of NHL

\begin{tabular}{|c|c|c|c|c|}
\hline \multirow[t]{2}{*}{ NHL type } & \multirow[t]{2}{*}{ Subtypes of NHL } & \multicolumn{2}{|c|}{ Ki-67 PI } & \multirow[t]{2}{*}{ Total } \\
\hline & & $<45(\%)$ & $>45(\%)$ & \\
\hline B-cell & DLBCL & $11(22.4)$ & $38(77.6)$ & 49 \\
\hline \multirow[t]{8}{*}{$(n=94)$} & CLL/SLL & $15(93.8)$ & $1(6.2)$ & 16 \\
\hline & Plasma cell type & 10(83.3) & $2(16.7)$ & 12 \\
\hline & Follicular & $4(66.7)$ & $2(33.3)$ & 6 \\
\hline & Lymphoblastic & $2(66.7)$ & $1(33.3)$ & 3 \\
\hline & Lymphoma B-Cell type & & & \\
\hline & Mantle cell lymphoma & $3(75)$ & $1(25)$ & 4 \\
\hline & Burkitt & 0 & 3 & 3 \\
\hline & MALT & 1 & 0 & 1 \\
\hline T-cell & Peripheral T-Cell Lymphoma NOS & $3(75)$ & $1(25)$ & 4 \\
\hline \multirow[t]{2}{*}{$(n=9)$} & Anaplastic Large Cell Lymphoma & $2(40)$ & $3(60)$ & 5 \\
\hline & Total & 51 & 52 & 103 \\
\hline
\end{tabular}

Table 3: Mean Ki-67 proliferative index (PI) in NHL

\begin{tabular}{lccccc}
\hline NHL subtypes & No. (\%) & Mean & SD( \pm ) & Minimum & Maximum \\
\hline DLBCL & $49(47.5)$ & 58.02 & 15.74 & 25 & 90 \\
CLL/SLL & $16(15.5)$ & 26.0 & 10.68 & 10 & 50 \\
Plasma cell type & $12(11.6)$ & 30.6 & 25.15 & 15 & 95 \\
Follicular & $6(5.8)$ & 45.0 & 19.49 & 25 & 80 \\
Lymphoblastic & $3(2.9)$ & 74.2 & 29.6 & 40 & 90 \\
B-Cell type & & & & & \\
Mantle cell lymphoma & $4(3.9)$ & 28.75 & 17.01 & 15 & 50 \\
Burkitt & $3(2.9)$ & 94.3 & 4.04 & 90 & 98 \\
MALT & $1(0.9)$ & 25.0 & - & 25 & 25 \\
Peripheral T-Cell & $4(3.9)$ & 46.9 & 29.25 & 25 & 90 \\
Lymphoma NOS & & & & & \\
Anaplastic Large Cell & $5(4.8)$ & 51.6 & 9.76 & 40 & 63 \\
Lymphoma & & & & & \\
Total & 103 & 48.05 & 17.85 & 10 & 98 \\
\hline
\end{tabular}

\section{RESULTS}

In this study, there were 77 males and 26 females with a male to female ratio of 2.9:1. Ki-67 is expressed $>45 \%$ in 38 males and 14 females. Regarding age less than 60 years, Ki-67 expression $>45 \%$ in 42 case and $<45 \%$ in 36 case. Regarding the age, gender, anatomical site, performance status and stage, they show no significant association with $\mathrm{Ki}-67 \mathrm{PI}$ at cutoff value $45 \%$ while the correlation of $\mathrm{Ki}-67 \mathrm{PI}$ more than $45 \%$ with presence of $\mathrm{B}$ symptoms, increase LDH level and IPI was highly significant $\left(P, x^{2}=0.001\right)$. In relation to site $50 / 103(48.5 \%)$ patients present with nodal origin of $\mathrm{NHL}$, while $53 / 103(51.5 \%)$ cases present with extranodal origin of NHL. In nodal origin of NHL, 29/50 (58\%) had $\mathrm{Pl}$ less than $45 \% .31 / 53(58.5 \%)$ cases of extranodal origin have $\mathrm{PI}$ more than $45 \%$.

48 cases $(46.6 \%)$ of $\mathrm{NHL}$ presented with B symptoms, out of which $36(75 \%)$ cases showed higher expression of Ki-67. Ki-67 expression less than $45 \%$ is present in $39(71 \%)$ cases without B symptoms. B symptoms are significantly associated with high expression of Ki-67 PI. 66 cases presented with increase LDH level. Among these 49 cases (74\%) express Ki-67> 45\%. Increase
LDH level is significant with Ki- 67 expression more than $45 \%$. In our study $78 / 103$ (75.7\%) patients presented with performance status zero \& one, in which 40/78 (51.3\%) cases had Ki-67 PI more than $45 \%$. Only $25 / 103(24.3 \%)$ cases present with restricted routine activities ,out of them 13/25(52\%) patients had Ki-67 PI less than $45 \%$. 69\% cases of low risk group have Ki-67 proliferation less than $45 \%$ and $89 \%$ cases of high risk group have $\mathrm{Ki}-67 \mathrm{PI}$ more than $45 \%$

Amongst total of 103 cases, 94 (91.3\%) were of B cell type and 9 $(8.7 \%)$ cases were of $\mathrm{T}$-cell type. Regarding the frequency of NHL, DLBCL (47.5\%) had highest frequency, followed by CLL/SLL $(15.5 \%)$ and Plasma cell neoplasm (11.6\%).

Highest mean Ki-67 index is present in Burkitt's lymphoma (94.3\%) followed by B-Cell lymphoblastic lymphoma (74.2\%) and DLBCL (58\%). Mean Ki-67 index include 30.6 for Plasma cell neoplasm,26.0 for CLL/SLL, 28.75 for Mantle cell, 25 for MALT lymphoma and 45 for follicular lymphoma. Significant association was found between high level of mean Ki-67 PI with aggressiveness of the disease subtypes. 


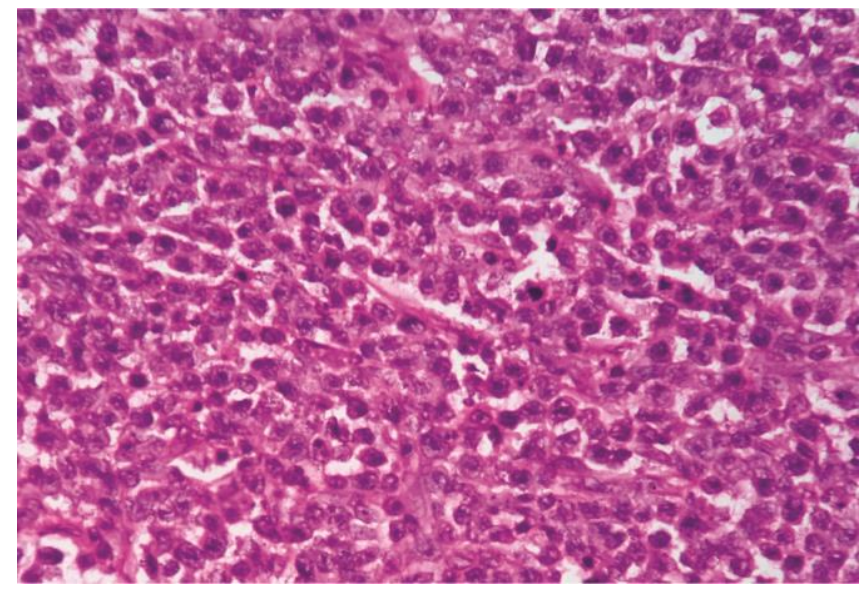

Fig 1: DLBCL show diffuse sheets of lymphoma cells. Nuclei are large, round, indented having vesicular chromatin and prominent nucleoli. (H\&E, 400X)

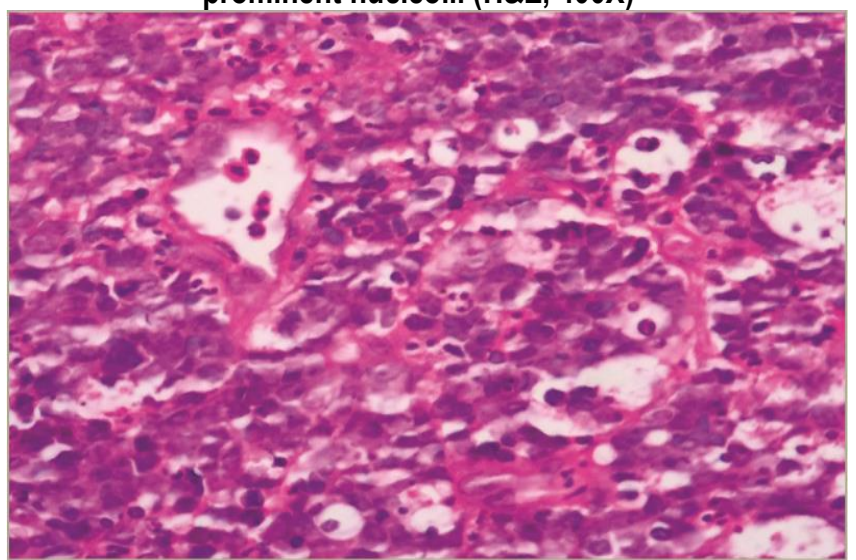

Fig 3: Burkitt lymphoma show medium sized neoplastic cells with "squaring off " of nuclear membrane with typical "starry-sky " appearance (H\&E, 400X)

\section{DISCUSSION}

The WHO classification of hematopoietic tumors is based on morphologic, immunophenotypic, genetic and clinical features. Ki$67 \mathrm{PI}$ is used as prognostic and diagnostic marker in NHL. The significance of Ki-67 with various clinical parameters is highly informative. Szczuraszek ${ }^{10}$ et al examined the correlation of Ki-67 expression with clinical parameters of the patients and their survival that patients of high Ki-67 PI have shorter survival $(p=0.03)$ but no significant correlation could be detected among Ki-67 expression and clinical or pathological parameters of the patients like type of $\mathrm{NHL}$, age and gender. This is partly in accordance with our study. Llanos et.al. ${ }^{11}$ suggest that Extra-nodal non-hodgkin's lymphoma of more than one site show the aggressive nature of the disease and our finding have no significant association with high Ki-67 PI. De Melo 5 et al. showed significantly higher proportions of Ki-67 positive cells in $\mathrm{T}$ cell $(11.2 \%)$ than in B cell $(2.9 \%)$ lymphoma $(P<0.001)$ in contrast to a study performed by Tominaga ${ }^{12}$ et al. that the percentage of Ki67 positive $(\mathrm{Ki}-67+)$ cells was lower, in T cell lymphomas than in B cell lymphomas, although the prognosis of $T$ cell lymphomas is considered worse than that of $B$ cell lymphomas. Our study is accordance with Broyedeet al. ${ }^{13}$ because we also found valuable difference of mean $\mathrm{Ki}-67 \mathrm{PI}$ within the $\mathrm{NHL}$ subgroups but using the cutoff value $45 \%$ of $\mathrm{Ki} 67 \mathrm{PI}$, we did not see any significant association of $\mathrm{Ki}-67 \mathrm{PI}$ in subtypes of $\mathrm{NHL}$. Hence the significance of mean Ki-67 PI to differentiate indolent versus aggressive

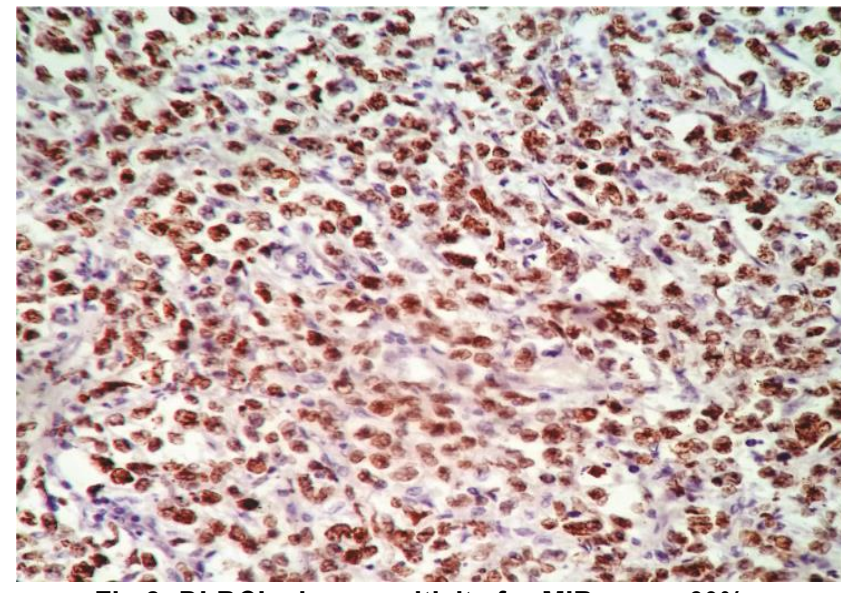

Fig 2: DLBCL show positivity for MIB score- $60 \%$

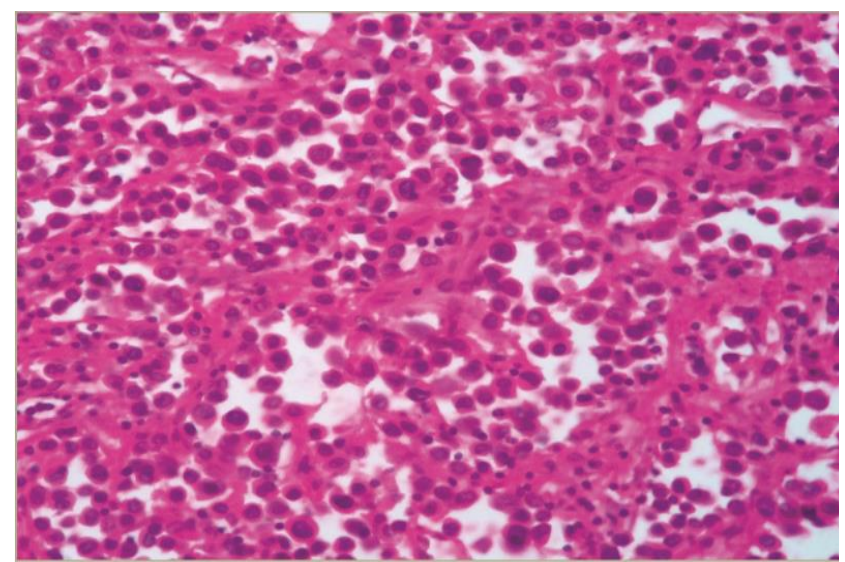

Fig 4: ALCL showing large neoplastic cells with round or horse shoe shape nuclei having amphophillic cytoplasm.

(H\&E,400x)

subgroups rather cutoff value of Ki-67, demonstrated the diagnostic value of Ki-67 PI to be followed in categorization of $\mathrm{NHL}$, as it is often difficult to grade NHL morphologically alone. Erum $\mathrm{Naz}^{14}$ suggests high Ki-67 PI have significant association in relation to anatomical site and presence of $B$ symptoms. He $X$, Chen $Z^{15}$ found that high $\mathrm{Ki}-67 \mathrm{PI}$ is negatively correlated with overall survival and disease free survival. However no significant association was seen between Ki-67 and LDH level, presence of B symptoms, Ann Arbor stage, extra-nodal involvement and performance status. Atif Ali ${ }^{16}$, Sanna Abdallah ${ }^{17}$ studied that mean $\mathrm{Ki}-67 \mathrm{PI}$ was less than $45 \%$ for indolent $\mathrm{NHL}$ and more than $45 \%$ for aggressive lymphoma. El-Esawy $\mathrm{BH}^{18}$ found significant correlation between high $\mathrm{Ki}-67 \mathrm{PI}$ and presence of $\mathrm{B}$ symptoms and involvement of extra-nodal site in NHL. Our study is in accordance to Erum $\mathrm{Naz}^{14}$, El-Esawy $\mathrm{BH}^{18}$.

\section{CONCLUSION}

Significant association of $\mathrm{Ki}-67 \mathrm{PI}>45 \%$ with presence of $\mathrm{B}$ symptoms and increase LDH level is seen in NHL. KI-67 PI cut-off value $45 \%$ is quite helpful to differentiate indolent versus aggressive nature of disease. Various clinical parameters age, gender, anatomical site and performance status do not show significant association in relation to Ki-67 PI cut-off value $45 \%$. Due to the lack of clinical data in relation to histological and immunochemical correlations, the exact picture of patient's outcome and survival is still unclear. Therefore, in future studies, 
there is a need to relate the laboratory investigations with clinical parameters to identify the exact picture in a large number of clinico-pathological studies for more conclusive observations.

\section{REFERENCES}

1. Swerdlow SH, Campo E, Harris NL, Pileri SA, Stein H, Thiele J, Vardiman JW: WHO classification of tumours of haematopoietic and lymphoid tissues. ed. 4. Lyon, IARC Press, 2008.

2. Urruticoechea A, Smith IE, Dowsett M. Proliferation marker Ki-67 in early breast cancer. J ClinOncol 2005; 23: 7212-7220.

3. Scholzen T, Gerdes J. The Ki-67 protein: from the known and the unknown. JCellPhysiol 2000; 182: 311-22.

4. Patruno R, Zizzo N, Zito AF, Catalano V, Valerio P, Pellecchia V et al. Microvascular density and endothelial area correlate with Ki-67 proliferative rate in the canine non-Hodgkin's lymphoma spontaneous model. Leuk/Lymphoma 2006; 47: 1138-1143.

5. De Melo N, Matutes E, Cordone I, Morilla R, Catovksy D. Expression of Ki-67 nuclear antigen in $\mathrm{B}$ and $\mathrm{T}$ cell lymphoproliferative disorders. J ClinPathol .1992; 45: 660-663.

6. Rosenwald A, Ott $G$. Burkitt lymphoma versus diffuse large $B$ cell lymphoma. Ann Oncol 2008; 19 (Suppl 4): iv 67-69.

7. Taylor CR, Shi SR, Barr NJ And Wu N. Techniqwes Of Immunochemistry: Principle, Pitfalls And Standardization, In Dabbs D. Diagnostic Immunochemistry, 3rd Edition, Churchill Livingstone, Elsevier: Philadelphia; 2010: 5-48.

8. His, E.D., S. Yegappan. Lymphoma immunophenotyping: a new era in paraffin-section immunohistochemistry. AdvAnat Pathol.,2001; 8: 218-239.

9. Pich A ,Ponti R, Valente G, et al. MIB-I,Ki-67 and PCNA scores and DNA flowcytometry in intermediate grade malignant lymphoma. J Clin Pathol. 1994:47:18-22.

10. SzczuraszekKatarzyna. K, Mazur. G, Jelen. M, Dziegiel. P, Surowiak.P and M Zabel.M. Prognostic significance of Ki-67 Antigen expression in Non-Hodgkin's Lymphomas. Anticancer research 2008; 28:1113-1118

11. Llanos M, Alvarez-Arguelles $\mathrm{H}$, Aleman R, Oramas J, Diaz Flores L, Batista N. Prognostic significance of Ki-67 nuclear proliferative antigen, bcl-2 protein, and p53 expression in follicular and diffuse large B-cell lymphoma. Medical Oncology 2001; 18: 15-22
12. Tominaga $K$, Yamaguchi $Y$, Nozawa $Y$ Abe $M$ Wakasa $H$. Proliferation In Non-Hodgkins Lymphomas As Determined By Immunohistochemical Double Staining For Ki-67. Hematol Oncol 1992; 10: 163-169.

13. Adi Broyde, Olga Boycov, Yulia Strenov. Role and prognostic significance of the Ki-67 index in non-Hodgkin's lymphoma Am. J. Hematol. 2009; 84:338-343.

14. Erun Naz, Talat Mirza, Sina Aziz , Adnan Ali; Correlation of Ki-67 proliferative index with clinical and pathological features on tissues section of non-Hodgkin lymphoma by immunostaining 2011, Journal of Pakistan medical association, volume 8, august 2011:748-752

15. He X, Chen Z, Fu T et al. Ki-67 is a valuable prognostic predictor of lymphoma but its utility varies in lymphoma subtypes: evidence from a systematic meta-analysis. BMC Cancer, 2014; 14: 153.

16. Atif Ali Hashmi, Zubaida Fida Hussain, Naveen Faridi, Amna Khurshid; Distribution of Ki-67 Proliferative Indices among WHO Subtypes of Non-Hodgkin's Lymphoma: Association with other Clinical Parameters Asian Pac J Cancer Prev, 2014;15 : 8759-8763 17. Sanaa Abdallah Mohmmed Omer. Detection of Cyclin D1 Protein and Ki-67 among Sudanese B lymphoma Patients European Academic Research Vol.III, Issue 9/December 2015; 10246-10257.

18. El-Esawy BH, Alghamdy AN, El Askary; A Research Journal of Medicine and Medical Sciences, 10(1) January 2015, Pages: 1-6.

\section{Source of Support: Nil. Conflict of Interest: None Declared.}

Copyright: (c) the author(s) and publisher. IJMRP is an official publication of Ibn Sina Academy of Medieval Medicine \& Sciences, registered in 2001 under Indian Trusts Act, 1882.

This is an open access article distributed under the terms of the Creative Commons Attribution Non-commercial License, which permits unrestricted non-commercial use, distribution, and reproduction in any medium, provided the original work is properly cited.

Cite this article as: Matadeen Meena, Jayanti Mehta. Association of Ki-67 Proliferative Index with Clinico-Pathological Features of Non-Hodgkin's Lymphoma Classified According to WHO (2008). Int J Med Res Prof. 2016; 2(4):103-07. 